\title{
"Fazer emergir o masculino": noções de "terapia" e patologização na hormonização de homens trans*
}

\author{
Cleiton Vieira** \\ Rozeli Maria Porto***
}

\section{Resumo}

Descreve-se as noções de "terapia" hormonal em cenários medicalizantes nos quais homens transexuais se movem na constituição de transições de gênero. Em meio aos acessos e práticas à (auto)administração de ésteres de testosterona (cipionato e/ou propionato), esses sujeitos acionam a ideia de "terapia" - seja para se afastar ou para reiterá-la -, levando-nos a uma reflexão sobre a atual classificação da transexualidade como doença mental. Realizou-se pesquisa etnográfica em grupos de ativismo trans no Brasil com entrevistas em profundidade no período de 2014 a 2015.

Palavras-chave: Homens Trans, Testosterona, Doença Mental, Identidade, Antropologia da Saúde.

* Recebido em 15 de novembro de 2016, aceito em 03 de julho de 2018. Somos gratos aos interlocutores da pesquisa, bem como ao apoio financeiro, na forma de bolsa de mestrado ao primeiro autor, da Coordenação de Aperfeiçoamento de Pessoal de Nível Superior que possibilitou a realização da investigação, e pelas observações dos/as pareceristas anônimos/as do periódico. Uma versão preliminar deste artigo foi apresentada na 30 Reunião Brasileira de Antropologia, realizada entre os dias 3 e 6 de agosto de 2016, João Pessoa/PB.

** Doutorando em Antropologia Social pela Universidade Federal do Rio Grande do Norte (UFRN), Natal, RN, Brasil. Visiting Research Scholar na University of Arizona' School of Anthropology e Institute for LGBT Studies. Pesquisador do grupo Gênero, Corpo e Sexualidade (GCS/UFRN). Bolsista CAPES de Doutorado no País e Sanduíche no Exterior. cleiton.vsr@gmail.com / https://orcid.org/0000-0002-8852-6212.

*** Professora Associada I do Departamento de Antropologia e do Programa de PósGraduação em Antropologia Social, da Universidade Federal do Rio Grande do Norte (UFRN), Natal, RN, Brasil. Pesquisadora do grupo Gênero, Corpo e Sexualidade (GCS/UFRN), da Red del Laboratorio Iberoamericano para el Estudio Sociohistorico de las Sexualidades, Espanha (RED LIESS/UPO) e do Núcleo de Identidades de Gênero e Subjetividades (NIGS/UFSC). rozeliporto@gmail.com / https://orcid.org/0000-00015318-1931. 
"Making the Masculine Emerge": Notions of "Therapy" and Pathology in the Hormonization of Trans Men

\begin{abstract}
The paper describes notions of hormonal "therapy" related to the medicalized situations through which transsexual men move in the constitution of gender transitions. Among the accesses and practices of self- administration of testosterone esters (cypionate and/or propionate), these subjects trigger the idea of "therapy" - either to avoid or reiterate it -, leading us to reflect on the current classification of transsexuality as a mental illness. Ethnographic research was conducted among trans activist groups with in-depth interviews in 2014 to 2015.
\end{abstract}

Keywords: Trans Men, Testosterone, Hormonal Health, Mental Illness, Identity, Health Anthropology 


\section{Introdução}

Este artigo se detém na relação que homens trans ${ }^{1}$ estabelecem com determinadas noções êmicas de terapia, e, consequentemente, com noções de doença, as quais são manejadas em meio a (auto)administração de ésteres de testosterona. Como se observa na pesquisa, os caminhos e as práticas que envolvem a constituição de processos de hormonização são compostos por movimentos em torno de uma aproximação e de um afastamento da patologização num cenário de medicalização. Na primeira parte do trabalho, realiza-se um breve panorama a respeito da classificação da transexualidade como uma doença mental por parte dos saberes médicos-psi, detendo-se no tratamento dado pelos manuais de saúde em vigor que a conceituam como "disforia de gênero" ou "transtorno de identidade de gênero". No segundo momento, ilustram-se os usos das noções de terapia e doença em meio às aplicações de hormônios sintéticos por esses sujeitos, processo esse "carnal e bioquímico", narrado pelos interlocutores da pesquisa como parte de suas "transições de gênero".

A "terapia hormonal", como parte de um itinerário terapêutico ${ }^{2}$ outorgado pelos saberes médicos-psi à transexualidade,

1 A transexualidade é reclamada pelos homens trans como matéria de gênero, e não de habitus erótico - que tem sido colocado como sinônimo comum de "sexualidade" (cf. Simões e Carrara, 2014). Como homem trans, entende-se os sujeitos que, tendo sido classificados ao nascimento como mulheres, reivindicam não ter encontrado a correspondência esperada socialmente entre anatomia tomada como dada e gênero, demandando reconhecimento político, biomédico, social e cultural enquanto homens. Portanto, conceituações que os coloquem como "fêmeas biológicas" não correspondem com suas realidades, tratando-se de uma atribuição revestida ineficazmente de qualidade científica neutra, mas que está carregada de pré-noções.

2 Itinerário terapêutico é o percurso de uma pessoa em busca de alívio e/ou cura de suas aflições. Inicia-se com o diagnóstico da enfermidade, seguida pela procura de solução. Nessa trajetória participam vários sujeitos - parentes, amigos, conhecidos, vizinhos, especialistas diversos -, os quais oferecem diferentes interpretações, possibilidades e/ou soluções de cura para o sofrimento (Langdon, 1994). Cf. Vieira e Barros (2007). Mesmo que a transexualidade seja observada aqui como uma forma diversa de expressão de gênero e não como doença, os 
entendimento proveniente de um arcabouço medicalizante, é ressignificada por homens trans como modos de ser que não estão apartados de relações que se inserem num mercado farmacêutico, na vigilância dos especialistas e no controle dos corpos. Nesse sentido, este trabalho não pretende esgotar a complexidade dos usos e noções manejadas com a prática de hormonização pelos sujeitos, mas lançar notas sobre uma certa apropriação de modos, técnicas e conhecimentos médicos para compor um processo político-corporal de autonomia sobre si mesmos.

Observa-se que a temática da masculinidade e do "ser homem" tem estado presente em recentes pesquisas sobre homens trans no Brasil (Ávila, 2014; Vieira, 2015; Oliveira, 2015). A constituição de mecanismos que possibilitem a transição de gênero feminino para masculino tem sido, com diferentes ênfases, objeto de preocupação de pesquisadores no país. A matéria tem potencial para descrever também outras nuances da vida cotidiana de homens trans, como as pesquisas com mulheres transexuais $e$ travestis que demonstraram ser o gênero feminino um dos principais elementos que acionam violências (Bento, 2014). Contudo, não se objetiva aqui centrar a hormonização em termos de ser homem em si, mas refletir sobre o lugar desse processo no âmago da medicalização da transexualidade que, no movimento da patologização, desumaniza e afasta da existência diferentes possibilidades de pessoa que também são recortadas pela transgeneridade.

Este trabalho ${ }^{3}$ parte de observação participante em etnografia realizada nos anos 2014 e 2015, entre grupos de ativismo trans no Brasil, bem como do uso de entrevistas em profundidade para reconstrução biográfica das trajetórias de homens trans. Muito embora tenham feito parte do corpus da pesquisa sujeitos das

protocolos médicos-psi instituem itinerários que são confrontados e reinterpretados pelos sujeitos.

${ }^{3}$ O texto flui recorrendo ora a tempo verbal da primeira pessoa do singular e ora à primeira pessoa do plural. O primeiro autor realizou o trabalho de campo, mas o artigo foi moldado analiticamente e escrito por ambos os pesquisadores que o assinam. 
regiões Centro-Oeste, Sudeste e Sul, devido ao deslocamento de ativistas pelo país ter possibilitado o contato com interlocutores, a pesquisa se concentrou no contexto nordestino. Com o acompanhamento de atividades pessoais e coletivas de um grupo ativista de homens trans na cidade de $\mathrm{Natal} / \mathrm{RN}$, seguiu-se à participação em congressos de militância $\mathrm{LGBT}^{4}$ e ao encontro face a face com tais colaboradores ${ }^{5}$ nos estados potiguar e paulista.

O interesse primordial desta pesquisa era entender como é vivido o processo de transição de gênero de homens trans, principalmente no que concerne à construção de formas de lidar com exclusões sociais de diferentes tipos no campo do acesso ao cuidado em saúde, ao emprego, de mudanças corporais $e$ identidade (Vieira, 2015). Mesmo que as considerações realizadas aqui não possam ser afastadas das interações com um conjunto maior de colaboradores indiretos, foi reunido um total de quinze homens trans entrevistados. As condições sociais dos sujeitos mostraram-se niveladas às classes populares, tanto por causa das redes de parentesco dessas pessoas corresponderem a trabalhadores assalariados formais e/ou informais, como pelas condições de acesso a recursos sociais e econômicos daí desencadeados. Quanto aos sujeitos que foram expulsos de casa devido à transexualidade, experiências de precariedade econômica e social estiveram presentes quando de suas reconstruções de relações de afeto $e$ ajuda mútua.

Não se acompanhou, contudo, nenhum serviço de saúde in situ, mesmo que as relações com tais instituições e profissionais tenham surgido de algum modo. A ausência do contato direto com hospitais ou ambulatórios se deve às trajetórias de homens trans que, em suas transições de gênero, estiveram majoritariamente às margens dos setores de saúde, pública ou privada. Serviços no âmbito da atenção básica em saúde mostraram-se, portanto, de

${ }^{4}$ Lésbicas, Gays, Bissexuais, Travestis e Transexuais.

${ }^{5}$ Seguimos as recomendações de Cláudia Fonseca (2010), a fim de preservar o anonimato dos interlocutores, embaralhando seus dados para impedir a identificação. 
difícil acesso quando da assunção da transexualidade em suas vidas. Mesmo assim, dois interlocutores, um proveniente de João Pessoa/PB e outro de São Paulo/SP, chegaram a fazer parte da política de saúde do Processo Transexualizador em suas respectivas localidades. $\mathrm{O}$ primeiro abandonou $\mathrm{O}$ atendimento devido à obrigatoriedade das terapias coletivas, $e$ o segundo se manteve no serviço ambulatorial público, dentre outros motivos, porque não pode arcar com os dispêndios no setor privado.

Contudo, a administração de testosterona realizada por todos os interlocutores, em algum momento ou mesmo durante todo o tempo, se deu por conta própria com a compra de receitas $e$ ampolas junto a vendedores para praticantes de musculação ou pelo seu compartilhamento entre amigos, pela ida ao médico clínico geral ou endocrinologista no setor privado, ou ainda pela intermediação por conhecidos junto a médicos no setor público. Nesse sentido, este artigo articula diferentes caminhos e estratégias constituídas por homens trans às margens das atuais políticas de saúde nacionais para a população $\mathrm{LGBT}^{6}$, seja por sua limitada oferta ou pelas tensões, presentes nas interações nos serviços, que aumentam a precariedade do cuidado.

\section{A medicalização da transexualidade: (des)patologização e manuais de saúde}

A despatologização das identidades trans, que atualmente estão classificadas em três manuais de doença/saúde, é um dos motes principais de um movimento nacional $e$ internacional de ativismo trans ${ }^{7}$ e de pesquisas em universidades, com proporções

\footnotetext{
${ }^{6}$ Sobre políticas de saúde voltadas para a população LGBT no Brasil ver Mello et al. (2011); sobre o Processo Transexualizador no SUS, ver Almeida e Murta (2013) e Murta (2011).

7 A nível internacional, encontra-se a Campanha pela Despatologização Trans desde 2012 (cf. http://www.stp2012.info/old/pt/manifesto). Há um aumento de organizações ativistas de pessoas trans no Brasil e no exterior em prol de direitos, como o Instituto Brasileiro de Transmasculinidades (IBRAT), a Rede Nacional de Pessoas Trans no Brasil e a Associação Transmasculina do Ceará. Sobre o
} 
cada vez maiores. Embora parte desses estudos tente focalizar aspectos que não sejam da concepção direta de medicalização da transexualidade, eles convergem em registrar e demonstrar normalizações que requisitam corpos complementares em relações heterossexuais, bem como resistências políticas às normas de gênero ${ }^{8}$.

A patologia não está fixada sem força em compêndios. É o ar técnico, um saber especialista e pretensamente neutro, que propicia o espírito de um manual. Em seu escopo se realiza um lugar de autoridade nada individual, se é possível evocar escritos do começo do século XX como o de Marcel Mauss e Henri Hubert (2003) a respeito da força coletiva da técnica, ao descrever a magia. Michel Foucault (1988), já demonstrou mais de uma vez como o conhecimento especializado constituíra uma demanda pelo saber sobre o corpo operacionalizado pela medicina. Os manuais médicos estadunidenses detêm um grande apelo político e técnico sobre os sistemas de saúde pública, muito além de seu território nacional, sejam eles gratuitos ou não. Suas pesquisas médicas sobre a população estadunidense, inclusive, acabam por ser utilizadas como base para argumentar tratamentos e explicar doenças em outras regiões do planeta. O que nos dá prerrogativa para pensar um possível movimento de globalização ou internacionalização da noção ocidental (euro-estadunidense) de transexualidade. Raewyn Connell (2012) demonstrou, nesse sentido, que a categoria transexualidade se expande ao redor do mundo e entra em atrito com noções locais que têm explicado e nomeado experiências de mudança de gênero, como as travestis na América Latina e as hijras na Índia e adjacências. Para a autora, a globalização da

movimento para despatologização a partir dos homens trans, consultar o importante trabalho de André Oliveira (2015).

8 Entende-se aqui "gênero" como o "aparato mesmo de produção mediante o qual os sexos são estabelecidos", de modo que "ele também é um meio discursivo pelo qual "a natureza sexuada" ou um "sexo natural" é produzido e estabelecido como pré-discursivo (Butler, 2008:25). Nesse sentido, ele se inscreve por meio de relações sociais (Haraway, 2004) que compõem a capilaridade de uma sociedade normalizadora que requisita e produz corpos específicos (Foucault, 1988, 2012). 
transexualidade ${ }^{9}$ se insere em políticas maiores da metrópole do norte global que disseminam teorias, modos de vida, categorias, $e$ visões de mundo (Connell, 2014).

Segundo Berenice Bento (2010), o gênero passou a ser uma categoria diagnóstica no início dos anos 1980 com o Manual Diagnóstico e Estatístico de Transtornos Mentais, da Associação de Psiquiatria Americana. Para a autora, isso seguiria uma patologização que acontece por meio da incorporação de uma categoria cultural como categoria diagnóstica. Retomando Michel Foucault (1988) sobre a sociedade normalizadora acompanhada da perda da força da lei para regular nossas condutas na modernidade, Bento argumenta que essas categorias se fundem através da inteligibilidade do gênero por ações do Estado. Está no germe desse governo estatal um conjunto de saberes especialistas para o controle/gestão da população, pensada em suas diferentes especificidades num arcabouço genérico.

A patologização, isto é, a criação de categorias de doenças ou transtornos não se perfaz de maneira isolada. Ela se constitui como ferramenta de um quadro "ocidental" do processo de medicalização ${ }^{10}$ da vida humana que envolve um conjunto complexo de agentes sociais - pacientes, médicos, o mercado, Estados-nação, a opinião pública, movimentos sociais, entre outros - que transformam problemas humanos ou diferenças sociais $e$ culturais em problemas médicos (Conrad, 2007; Rosenberg, 2007). A chave desse processo, segundo Peter Conrad (2007), é a definição. "Isto é, um problema é definido em termos médicos, descrito usando linguagem médica, entendido através da adoção de um panorama médico, ou "tratado" com uma intervenção médica" (Conrad, 2007:5, tradução nossa). A própria definição anterior de um problema a ser considerado pode estar envolvida em uma empresa

\footnotetext{
9 Cf. Bruno Barbosa (2015) para um debate brasileiro da questão em torno da noção de "transglobalização".

${ }^{10}$ Para um panorama acerca da medicalização como objeto sociológico, cf. Conrad (2007). Para uma revisão acurada do campo antropológico brasileiro e sua ligação com cenário internacional, ver Sarti (2010).
} 
moral, que, na história da sociedade ocidental, medicalizou diferenças sexuais e de gênero. Como coloca Conrad, isso acontece pela medicalização do desvio, como aconteceu e acontece em relação à homossexualidade e à travestilidade; transformando, assim, aspectos da vida humana em patologias.

Nesse quadro, são as categorias diagnósticas que fazem o trabalho da definição e produzem o espectro de objetividade e de neutralidade do que é considerado doença (Rosenberg, 2007; cf. Sarti, 2010). Escondendo a subjetividade, as emoções e as interações presentes na relação médica do diagnóstico, prognóstico $e$ tratamento, formulam-se as doenças em si mesmas como entidades, mas tendo como localidade resolutiva a esfera individual (Conrad, 2007).

Assim, a classificação da transexualidade como doença mental é produzida enquanto um movimento de transposição de um fenômeno social e cultural para o terreno da racionalidade, do vocabulário e do controle médico. Essa transformação tem uma trajetória específica, cuja reverberação continua, inclusive, na fundamentação teórica atual das políticas de saúde para a população trans que têm sua difusão nos anos 1960, com a publicação de The transsexual phenomenon pelo endocrinologista e sexólogo alemão Harry Benjamin (Meyerowitz, 2002). Não significa dizer que esse momento seja apartado do histórico de desenvolvimento da gestão da vida em torno do corpo dimórfico (Foucault, 1988, 2012). Mas é com esse livro, no qual Benjamin indicaria os passos para se descobrir o "verdadeiro transexual", que se consagra o tratamento da transexualidade no meio médico (Rubin, 2003; Bento, 2006). O centro desse esforço em especificar diagnóstico e tratamento da transexualidade está na necessidade do corpo médico e sexólogo de separá-la da homossexualidade, também tratada, à época, nosologicamente (Rubin, 2003). Por isso Harry Benjamin muda o "diagnóstico" de "inversão sexual" para "inversão sexual total" (e depois para transexualismo) para designar os indivíduos "nascidos fêmeas", mas que "se sentem homens e querem a mudança de sexo" (Rubin, 2003:103, tradução nossa). 
Atualmente, há três manuais de saúde que reconhecem doenças referentes ao "diagnóstico de gênero". São o CID-10 ${ }^{11}$, editado pela Organização Mundial de Saúde (OMS) desde 1983; o DSM- $5^{12}$, organizado pela Associação Americana de Psiquiatria (APA); e as Normas de atenção, versão 7 (NDA7) ${ }^{13}$, da Associação Mundial Profissional para a Saúde Transgênero (WPATH). É interessante observar que enquanto o CID-10 manteve a mesma nomenclatura com a sua última atualização, o DSM-5 e as NDA-7 tentaram "suavizar" o diagnóstico, com a mudança de títulos.

Na última edição do CID-10, a transexualidade é classificada como "transexualismo" (transexualism), agrupada junto a outras cinco desordens de gênero na subseção "F64 - Transtornos de identidade de gênero", capítulo V - "Desordens mentais e comportamentais". Para o manual, transexualismo é conceituado como:

Um desejo de viver e de ser aceito como um membro do sexo oposto, frequentemente acompanhado de um senso de desconformidade com, ou de inadequação, com o sexo anatômico, e um desejo de realizar cirurgia e tratamento hormonal para tornar o próprio corpo tão congruente quanto possível com o sexo pretendido (OMS, ICD-10, online ${ }^{14}$, tradução nossa).

\footnotetext{
${ }^{11}$ Classificação Estatística Internacional de Doenças e Problemas Relacionados com a Saúde, edição 10. A $11^{a}$ versão desse manual, lançada em 2018 , mas em vigor a partir de 2022, nomeia a transexualidade como "gender incongruence" (incongruência de gênero) (ICD-11). Contudo, essa versão não foi considerada na análise, haja visto que ela não vigorava na época da pesquisa e da escrita do artigo, não sendo possível observar as relações $e$ as reverberações políticas estabelecidas pelas modificações instituídas. Essas mudanças, que necessitam de uma análise à parte, não encontraram unanimidade entre ativistas pela despatologização.

${ }^{12}$ Manual Diagnóstico e Estatístico de Transtornos Mentais, edição 5, mais conhecido pela sigla em Língua Inglesa DSM-5 (Diagnostic and Statistical Manual of Mental Disorders).

${ }^{13}$ Normas de atenção à saúde de pessoas trans e com variabilidade de gênero, edição 7.

${ }^{14}$ Cf. <http://apps.who.int/classifications/icd10/browse/2010/en\#/F64>.
} 
Como pode-se perceber, essa definição já apresenta um processo de cura: "tratamento hormonal" e "cirurgia" de redesignação sexual. Todos os procedimentos, sejam invasivos ou não, compreendem uma total adequação ao "sexo" expressado pelo "paciente". Bento (2006) chamará isso de "complementariedade heterossexual", concluindo que o diagnóstico $e$ o tratamento da transexualidade instrumentalizaram o cuidado em saúde para que o indivíduo correspondesse a uma coerência entre sexo, corpo e desejo. Assim, apresentar desejo sexual por homens, no caso de um homem trans, seria a prova cabal de que não seria um "transexual verdadeiro".

Atualmente, o manual da WPATH - as NDA-7 - compreende um cuidado em saúde específico para um sujeito com inconformidade com o gênero, mas que não se encaixaria na classificação de transexualidade. O que na prática mantém o poder do diagnóstico nas mãos dos psiquiatras e psicólogos.

Grande parte desses saberes e suas publicações normativas seguem contrários aos argumentos de pessoas transexuais $e$ transgêneras, que, tomando como ponto de partida seus lugares de cidadãs e cidadãos de direitos, buscam ter autoridade sobre seus próprios corpos, observando as práticas moralizantes envoltas no diagnóstico de gênero que circunscreve condutas e corpos específicos. As NDA-7 e o DSM-5 se utilizam do termo "disforia de gênero", diferente do CID-10. Para as NDA-7 (WAPTH), há uma diferença entre "não conformidade de gênero" $e$ a disforia, a segunda sendo apresentada claramente como uma patologia.

A disforia de gênero refere-se ao desconforto ou mal-estar causado pela discrepância entre a identidade de gênero de uma pessoa e o sexo a ela atribuído no momento do nascimento (e o papel de gênero associado e/ou características sexuais primárias e secundárias). Somente algumas pessoas com variabilidade de gênero experimentam disforia de gênero em algum momento das suas vidas (WPATH, 2012:5). 
Já no DSM-5 (APA):

Refere-se ao sofrimento que pode acompanhar a incongruência entre o gênero experimentado ou expresso e o gênero designado de uma pessoa. Embora essa incongruência não cause desconforto em todos os indivíduos, muitos acabam sofrendo se as intervenções físicas desejadas por meio de hormônios e/ou de cirurgia não estão disponíveis. O termo atual é mais descritivo do que o termo anterior transtorno de identidade de gênero, do DSM-IV, e foca a disforia como um problema clínico, e não como identidade por si própria (APA, DSM-5, 2013:451-2, grifo nosso).

As diferenças entre os manuais também se devem aos seus públicos específicos e ao caráter de alcance de cada compêndio. As NDA-7 se pretendem atualmente multidisciplinares, já o DSM-5, psiquiátrico. Os próprios tipos de doenças e de cuidado atendidos pelas diferentes classificações expõem o modo como entendem o tratamento de uma "enfermidade" e o caminho de perseguir o diagnóstico, variando em pretensão de objetividade e de saber disciplinar. Esse caminho da cura postulado pelos manuais, já que elenca doenças diagnosticadas, pretenderia um realinhamento para colocar "no lugar" gênero, corpo e habitus erótico.

Em todos os manuais, a chamada terapia hormonal é uma das terapias às quais devem se submeter os diagnosticados. Mesmo atualmente, a necessidade da cirurgia de redesignação sexual não alcançou muita relativização nas normas, ainda que diferentes pesquisas tenham mostrado que esse manejo corporal não tem sido requisitado por todas as pessoas trans (Bento, 2006; Alexandre, 2015; Ávila, 2014; Oliveira, 2015, Vieira, 2015). Tanto o DSM-5 como as NDA-7 se mostram dialogando com teorias sociais acerca da transexualidade e do gênero em geral, colocando-se como uma visão clínica, e abrangendo a construção do sexo ou do gênero como uma questão múltipla que envolve a biologia, a sociedade e a psiquê. Aliando-se, assim, ao modelo do ser "biopsicossocial" assumido pela medicina no começo do século XX (Sarti, 2010). No 
entanto, seria de se questionar o peso atribuído a cada um desses domínios no cotidiano da prática médica.

A seguir as NDA-7 da WPATH serão tomadas como base de comparação entre as normas institucionalizadas e o acesso ao cuidado em saúde por homens trans. Isso se deve à atuação histórica dessas normas, de alcance mundial, e à força de influência contínua que têm em normatizar a definição, o diagnóstico e o processo terapêutico da disforia de gênero. As NDA-7 e o DSM-5 têm sido o escopo para a cobertura médico-legal do Processo Transexualizador no SUS, bem como para a criação dos ambulatórios para o atendimento em saúde e acompanhamento social para pessoas transexuais e travestis no Brasil. É preciso, assim, compreender que os ambulatórios do serviço transexualizador, com suas reuniões em grupo, sessões com psicológicos e consultas médicas, têm se tornado locais de processos de subjetivação de homens e mulheres transexuais, os quais se envolvem de elementos afetivos cruciais na relação com documentos e burocracias na constituição de si mesmos (cf. Alexandre, 2015).

\section{Da disforia à transição de gênero: os "hormônios sexuais" e a terapia hormonal}

No Brasil, setores estatais em saúde são os únicos espaços normatizados para assistir medicamente o "diagnóstico" e o "tratamento" da "disforia de gênero". Há pouco alcance por parte do Ministério da Saúde e do Conselho Federal de Medicina em regular o atendimento a pessoas transexuais entre médicos e psicólogos no setor privado. Esse é um mercado em crescimento e movimenta recursos financeiros vultuosos daqueles que podem pagar, sendo uma alternativa para a demora das filas para consultas e procedimentos efetivos no setor público. São pessoas que podem não ter acesso a capitais pregressos na família, mas que realizam o "juntar" dinheiro para arcar com os dispêndios de cirurgias $e$ hormonização. Esse cenário do parco atendimento aliado à rigidez do diagnóstico faz com que um grande contingente de mulheres e 
homens trans tentem acumular um saber médico que lhes dê possibilidade de usar testosterona ou estrogênio por conta própria, além de outras técnicas para concretizar e manter a transição de gênero.

No país, o Sistema Único de Saúde (SUS), por meio do programa chamado "Processo Transexualizador"15, revisto pela Portaria n. 2.803, de 19 de novembro de 2013, operacionaliza a assistência médica para essa transição. O programa segue as orientações dos manuais de doença internacionais já citados anteriormente. O diagnóstico da transexualidade é realizado a partir de uma exaustiva avaliação que inclui: histórico completo do caso, testes psicológicos e sessões de terapia, como mostrou Berenice Bento (2006) em sua pesquisa sobre o tema no Brasil.

No final de todos os testes e terapias é que a equipe médica encaminha a pessoa trans para a cirurgia de transgenitalização. $\mathrm{Na}$ prática, são poucos aqueles que conseguem chegar ao final desse processo devido aos poucos procedimentos realizados pelo SUS, à escassez de recursos, aos poucos profissionais envolvidos, e a grande demora e rigidez em seus protocolos guiados por normas alusivas à inteligibilidade do gênero (Bento, 2006). O que foi relatado por Bento no começo dos anos 2000 ganhou outros contornos recentemente.

A Portaria n. 2.803, já citada, ampliou os procedimentos ambulatoriais e hospitalares para a população de homens trans, incluindo as cirurgias de redesignação sexual, histerectomia, ooforectomia bilateral e mastectomia (CONITEC, 2012). A disseminação, embora limitada, de ambulatórios voltados especialmente para a saúde da população transexual, travesti e gay possibilitou extraoficialmente descentralizar o foco na cirurgia. A ida ao médico e ao psicólogo para se ter acesso a receitas legais para a compra de ésteres de testosterona pode ser o único objetivo dentro desse atendimento em saúde para muitos sujeitos. Nesse sentido, o processo de hormonização auxiliado ou não por médicos não é visto de forma unânime como um caminho de cura. Há uma

${ }^{15}$ Para observar a formação histórica dessa política, ver Daniela Murta (2011). 
preocupação, de homens trans, em fugir da patologia, rejeitando, inclusive, o uso do termo "terapia hormonal", como já mencionado. Terapia pode se tornar sinônimo de doença porque a evocaria.

Como visto, todo o contexto da patologia ${ }^{16}$ da transexualidade atribui à terapia hormonal uma grande efetivação do "tratamento". Por mais que o antigo orientador da WPATH, Harry Benjamin, tenha defendido em seus termos que a "inversão sexual" é total entre transexuais, levando-os a querer sempre a cirurgia de redesignação sexual, essa terapia seria o passo fundamental que possibilitaria ao corpo a saúde que teria sido retirada por uma doença mental (Rubin, 2003). Além disso, todos os interlocutores desta pesquisa atribuíam seus cuidados em saúde ao acompanhamento "correto" de suas "taxas" hormonais por um endocrinologista.

Francisco (20 anos), um dos interlocutores, observa, a partir de sua experiência em também orientar outros homens trans sobre a transição de gênero, que o uso de testosterona é uma das primeiras questóes trazidas por esses sujeitos ao "se descobrirem". Apesar da ingestão contínua de hormônios representar um "estado de felicidade" por propiciar mudanças corporais visíveis, Francisco lembra que não é ela que "ativa" a identidade (Hall, 2010) que criaria a sua experiência de transexualidade. É algo anterior: um entendimento proporcionado por um exame subjetivo que constrói o modo como percebe a si mesmo, para, assim, procurar a hormonização. ${ }^{17}$ Ele diz:

É um processo que você tem uma felicidade imensa quando você toma a primeira injeção de hormônio e já chega em casa assim: "caralho!"; e você se olha no espelho e diz: "puta que pariu, tá nascendo um pelo aqui". E não é assim, na verdade, demora um tempo para crescer, mas você fica tão

\footnotetext{
${ }^{16} \mathrm{O}$ que inclui análise psicológica (Rubin, 2003).

${ }^{17}$ É interessante ressaltar que a hormonização não é vista ou acionada sozinha para produção e transição de gênero corporal, uma vez que as práticas de exercícios físicos/esportes como musculação (Vieira, 2015), e seus regimes alimentares próprios também participam da masculinização.
} 
empolgado que entrou a agulha e você: "caralho, boy, já tá nascendo barba aqui, caralho boy". É aquilo que eu falei pra você, a transição começa quando você se entende como trans, não é com a hormonioterapia. Porque quando você se entende como trans, você já se olha no espelho e você já se vê diferente, tá entendendo? (Francisco, 20 anos, em entrevista, mar. 2015).

Quando conheci Francisco, era comum que se utilizasse do termo "hormonioterapia" para se referir ao uso de testosterona sintética. Com o passar do tempo durante o trabalho de campo, é possível perceber uma mudança discursiva. Posteriormente, ele se preocupa mais com a noção de terapia, lembrando que não tem nenhuma doença. É interessante observar que a inserção em redes de ativismo trans tenha incitado a mudanças de consciência ou ao uso dos termos diferentes. O processo médico, com seus atendimentos, os exames ambulatoriais, as portarias com forças de lei, na verdade são uma forma de atingir mudanças corporais desejadas para a sua transição. O uso da palavra "terapia" implicaria uma apropriação de um idioma médico, e não uma patologia de si mesmo.

A noção de "terapia" tem assumido uma polissemia difícil de rastrear na própria medicina, o que dificulta até mesmo sua conceituação como "ponto de partida". Joffre Rezende (2010), médico especialista em Doença de Chagas, para usarmos termos da ciência médica, argumenta que a palavra remete ao cuidado dos enfermos para curar suas doenças. No entanto, a "confusão", segundo o autor, advém da sinonimização de termos como terapêutica - saber médico que estudaria as terapias possíveis - e tratamento - conjunto de terapias empregadas.

No entanto, diversos homens trans concebem que os profissionais de saúde, no que tange a transição de gênero, entrariam como assistência relacionada a problemas médicos provenientes de um mal manejo de informações ou complicações corporais. E não como diagnosticadores. A terapêutica seria antes a da prevenção de desestabilizações hormonais e de alívios da aflição causados pelo estigma e pelo manejo corporal sem assistência, e 
não a de um conjunto de processos curativos visando a "disforia de gênero" para dar lugar a um indivíduo curado. Até mesmo quando se usa o termo "disforia" para se referir aos "desgostos" com formas tidas como femininas no corpo, o conceito pode ser virtualmente despatologizado. Inácio (21 anos), por exemplo, ao me contar seus encontros com a psicóloga, relata que irá requisitar um período mais curto entre as sessões, o que ele justifica a partir do aumento de conflitos com seu corpo, o qual não expressaria sua subjetividade. Quando lhe pergunto sobre a transexualidade ser classificada como uma doença mental, ele me responde:

Não, eu me vejo como um menino preso no corpo de uma menina. Eu não me vejo como um doente, eu não me vejo de modo algum como um doente, um doente mental, não. [...] (Inácio, 21 anos, em entrevista, nov. 2014).

Surpreso com o uso da palavra "disforia" para descrever seu sofrimento, questiono sobre a relação desse termo com a patologização. Ele explica:

Disforia pelo que eu pesquisei é o contrário de euforia. Euforia é quando você tá muito feliz, tá eufórico, você tá que não se aguenta, e a disforia é completamente o inverso disso. Porém, em homens trans isso ataca de forma completamente mais violenta, porque você tá num corpo que você não pediu pra nascer, então isso é dez vezes pior porque, certo, você pode se chatear com alguma coisa, mas eu acredito que você não olha no espelho e pensa que está se sentindo preso num corpo que não é seu. Então a disforia pra mim são esses momentos no mês que eu tenho uma depressão. Eu acho que se não fosse pela minha mãe eu estava em depressão fodido agora por isso porque são momentos no mês que eu fico pra morrer (Inácio, 21 anos, entrevista, nov. 2014).

Num exercício reflexivo de oposição de ideias, Inácio põe em relação as categorias "disforia" e a "euforia", essa que já foi um 
diagnóstico psiquiátrico independente ${ }^{18}$, mas que hoje compõe um conjunto de outros descritores para se referir a uma gama de patologias mentais. Trata-se de uma operação semântica poderosa com a qual Inácio se afasta da patologia. O vernáculo "euforia" aparece atualmente no senso comum como um estado emocional que não tem relação com nenhuma condição médica ou doença. Ao paralelizar disforia e euforia, Inácio afasta a primeira do seu uso em categorias patológicas, e lhe carrega de sentido para descrever sua vida sem se atrelar ao diagnóstico associado à transexualidade. A palavra na sua força médica é diluída nesse movimento aproximativo, colocando-a numa trajetória etimológica despatologizante. Ela é o modo como Inácio nomeia o desespero ao não encontrar correspondência entre si mesmo e seu próprio corpo, uma vez que não encontra reflexo com as disposições sociais que estão sendo demandadas cotidianamente. Os termos de uma doença são utilizados para explicar uma tristeza profunda intensificada quando seu corpo apresenta o que é considerado "coisa de mulher", como a menstruação recorrente mês a mês quando não se utiliza de testosterona sintética.

Numa sociedade cujas normas se inscrevem na produção de corpos como um mecanismo de gestão da população, a menstruação demanda cuidados que não estão dissociados de noções de gênero nem da produção do sexo que separam os sujeitos na hierarquia social. Inácio relata ainda momentos raros nos quais foi tomado como mulher em público, de modo que o conceito de não estar eufórico consigo mesmo vai de encontro à inteligibilidade de gênero demandada nas relações em que está inserido. Um sofrimento social e não um conflito individual.

É seguindo esse panorama de sofrimento que as NDA-7, da WPATH, compreendem que a hormonização é restrita às pessoas

\footnotetext{
18 Segundo o Barnhart Dictionary of Etymology (1988), euforia é um termo médico setecentista para descrever uma condição extrema de contentamento (principalmente quando doença) e um termo de origem grega para a capacidade de se sentir bem facilmente. O termo populariza-se na década de 1930 ao ser associado ao uso de cocaína.
} 
diagnosticadas disfóricas por psicólogo ou psiquiatra. O manual orienta que sejam seguidos alguns passos para que a "terapia hormonal" dê início. Além do diagnóstico por um psicólogo, como já mencionado, o paciente deve atender a alguns critérios, como: a) "capacidade para tomar uma decisão com pleno conhecimento $e$ para consentir o tratamento"; b) "maioridade em um determinado país"; c) consentimento informado; e c) controle de problemas de saúde física ou mental, caso estejam presentes (WPATH, 2012:38).

O manual ainda diferencia quatro tipos de terapia hormonal que se unem em um longo processo terapêutico: 1) início da feminilização/masculinização hormonal; 2) manutenção dos índices hormonais antes da retirada das gônadas; 3) terapia hormonal permanente. O quarto tipo é chamado de "terapia ponte", aplicada pelo médico à pessoa trans que já tenha iniciado a hormonização sem acompanhamento médico. Visa um período de um a seis meses antes da conclusão do diagnóstico, e não se caracteriza como uma despatologização, mas apenas um atendimento emergencial.

Entretanto, a hormonização da grande maioria de homens trans colaboradores desta pesquisa tem se dado por conta própria. Alberto (18 anos) descreve quais ésteres de testosterona aplica, os modos $e$ as formas de entender o progresso dessas injeçóes subcutâneas. Injetando os hormônios em intervalos de 21 dias, ele diz:

Eu comecei tomando a testosterona só porque eu não consegui marcar [consulta] de jeito nenhum. Eu comecei ainda tinha 17. A gente está em dezembro e eu comecei em fevereiro deste ano. Fazem 10 meses. [A aplicação] é na bunda. Na bunda com uma agulha gigante (Alberto, 18 anos, em entrevista, dez. 2014).

Pergunto, então, qual é a marca de testosterona que utiliza. Ele me responde que, como a Durateston saiu do mercado ${ }^{19}$, teria

\footnotetext{
${ }^{19} \mathrm{Na}$ época de realização desta pesquisa foi relatada uma dificuldade de encontrar nas farmácias o medicamento Deposteron. Para maiores considerações, ver Vieira (2015) e Oliveira (2015).
} 
começado a tomar hormônios comprados a partir de terceiros, $e$ não da farmácia. Para que essas compras e vendas se efetivem no mercado "ilegal" é preciso toda uma rede de contatos que conhecem fornecedores, mercadorias mais confiáveis e melhores preços. Esse circuito de compra e venda clandestino cresce devido a regulação cada vez maior que se constituiu no país.

A primeira regulação brasileira da testosterona sintética surge em 1998 com o controle de anabolizantes pela Secretaria de Vigilância Sanitária (SVS) do Ministério da Saúde. Em 2000, durante a gestão do Presidente Fernando Henrique Cardoso, o Brasil passa a regular ésteres dessa substância que ainda não haviam sido considerados. Conflui-se, assim, diretamente à gestão dos corpos da população, a ação efetiva de uma governamentalidade (Foucault, 2012). Apesar do controle rigoroso que foi estabelecido, como a inclusão do Código Identificador de Doenças do CID na receita médica, o consumo de testosterona tem sido feito de modo a ir além das receitas endocrinológicas. A substância mais frequente e desejada tem sido o propionato ou cipionato de testosterona, uma vez que homens trans percebem que são esses os tipos de ésteres que apresentam os melhores resultados $e$ os menores (embora ainda frequentes) causadores de complicações nos níveis hormonais e na saúde de modo geral ${ }^{20}$.

Nesse sentido, a testosterona sintetizada, na forma de medicamento controlado pelo Estado e utilizada por homens trans, pode ser vista como um "medicamento de gênero", como Débora Diniz e Rosana Castro (2011) conceituam o misoprostol ao se

\footnotetext{
${ }^{20}$ Os usos de hormônios sintéticos masculinizantes poderiam encontrar riscos como: a) policitemia, aumento de peso, acne, calvície, apneia do sono (provável aumento de risco); b) enzimas hepáticas elevadas (possível aumento de risco); c) desestabilização de certos transtornos psiquiátricos, doença cardiovascular, hipertensão e diabetes tipo 2 (possível aumento de risco na presença de fatores de risco adicionais; e d) perda de densidade óssea, cânceres de mama, cervical, ovário, uterino (sem aumento ou evidência de risco não concluinte ou não documentada) (NDA-7).
} 
referirem ao uso desse medicamento ${ }^{21}$ por mulheres para a indução do aborto (cf. Porto; Souza, 2017). Contudo, mesmo nesse quesito, a síntese da testosterona tem uma trajetória histórica diferenciada do misoprostol. Poderíamos pensar inicialmente que ambos teriam uma origem direcionada para doenças como hipogonadismo no caso do primeiro, e úlcera gástrica, do segundo (Diniz e Castro, 2011; ABEM, 2004). E, embora seus usos interfiram e componham processos corporais nos quais sujeitos são localizados a partir de suas identidades de gênero nas relações sociais, a trajetória da testosterona para se tornar um "hormônio sexual" masculinizante se refere a uma constituição generificada na ciência médica no século $\mathrm{XX}$.

Nelly Oudshoorn (1994) demonstra como se forma a criação desses hormônios (estrogênio e testosterona) e aponta para a relação entre diferentes agentes sociais e grupos, os médicos clínicos, os cientistas de laboratório e a indústria farmacêutica. No século XIX, a busca pela diferença entre homens e mulheres estava direcionada para os ovários e testículos, os quais guardariam a verdade sobre o corpo e o comportamento. No século $\mathrm{XX}$, os centros produtores de masculinidade $e$ feminilidade são erigidos como as secreções produzidas pelas gônadas que operariam essa diferenciação corporal e mental ligando gênero e anatomia. O que significa, nesse sentido, a constituição do paradigma bioquímico da medicina, antes centralizada num modelo biológico, e a emergência de uma endocrinologia sexual.

Na raiz das descobertas ou criações endocrinológicas está a medicalização da sexualidade e do corpo das mulheres, debatido $e$ analisado também no Brasil do final do século XIX por médicos no Rio de Janeiro. Assim, segundo Fabíola Rohden (2008), o interesse

\footnotetext{
${ }^{21} \mathrm{O}$ medicamento é utilizado como prevenção de úlceras gástricas, comercializado normalmente entre os anos de 1986 e 1991. Com a publicação de uma pesquisa informando que o medicamento era capaz de estimular contrações uterinas, sua circulação foi proibida pela ANVISA em 1991 (Mariani Neto et al., 1987). Mas ele continuou a ser utilizado institucionalmente - para os casos de aborto legal - e sua proibição aumentou o mercado clandestino, e um de seus usos volta-se para interromper a gravidez.
} 
nos hormônios é um interesse nos comportamentos diferenciados em função do sexo. Lucas Tramontano (2017) demonstra que isso reverbera na descrição química, conformando a diferença de gênero, a anatomia e sua atividade, quando analisa dois manuais de fisiologia e farmacologia. Ao considerar o desenvolvimento científico, o autor mostra que se descobre que não existe apenas um estrogênio, uma progesterona e uma testosterona, mas um grupo de moléculas "estruturalmente similares capazes de se ligar aos mesmos receptores e desencadear os mesmos efeitos metabólicos" (Tramontano, 2017:177). "Estrogênios" ou "progesteronas" passam a nomear um grupo, sendo que a primeira molécula a ser descrita é a própria progesterona, e o estrogênio é percebido como uma dupla de outras com estruturas diferentes entre si, a estrona e o estradiol.

No caso da testosterona, haveria um movimento diverso. O termo descreve uma única molécula, a mesma já descrita no século $\mathrm{XX}$; contudo, quando se observou um grupo de moléculas aproximadas como aconteceu com os estrogênios, não as chamou de "testosteronas", mas de androgênios. ${ }^{22}$ Tramontano chega à conclusão, com essa análise, que não é possível separar a molécula "testosterona", um fato da bioquímica, da testosterona enquanto a representação do masculino por excelência, principalmente porque não há neutralidade total na ciência e nem da divulgação dos seus "resultados". As diferenças anunciadas de modo tão veemente não se justificam porque a fisiologia humana não age de forma causal, linear e organizada. São os manuais, continua o autor, que organizam e simplificam o funcionamento do organismo. A informação sobre uma molécula vai ganhando objetividade $e$ organização causal quanto maior for sua aplicabilidade, seja para outro ramo do conhecimento (química geral para química orgânica, da bioquímica para a fisiologia, da farmacologia à prática clínica, do médico ao diagnosticado) ou para sua conformação em práticas cotidianas de interpretação no cuidado em saúde.

\footnotetext{
22 Segundo o autor, essa seria uma nomeação mais correta bioquimicamente porque haveria a necessidade de descrever melhor a função do grupo desses hormônios.
} 
A testosterona sintética, nesse sentido, pode ser considerada um medicamento de gênero por meio do qual os corpos são generificados $e$ as identidades corporificadas em termos de diferença sexual. Isso acontece por meio da confluência de múltiplos agentes e contextos, como os setores estatais, as políticas de saúde, o mercado e a indústria farmacêutica, os saberes biomédicos, bem como a ação política que envolve as demandas sociais e as práticas corporais de homens trans.

\section{Entre os recursos e os acessos à testosterona}

Para ter acesso às diferentes marcas de ésteres de testosterona disponíveis no mercado, é possível adotar uma infinidade de estratégias que também se localizam a partir de capitais disponíveis aos agentes. Nesse sentido, observa-se uma facilidade (ou um complicador a menos) proporcionada pela disposição de recursos financeiros excedentes, ou que sejam separados a duras penas. Estar inserido em uma família de trabalhadores, ser expulso de casa, trabalhar (sem qualificação) em empregos de baixa remuneração apenas para manter os custos básicos da própria alimentação e moradia e/ou de seus familiares, não obter inserção em redes de compra/venda de testosteronas ou de receitas, são alguns dos contextos que irão ser diferenciadores para que a hormonização se concretize, e, com isso, seja possível sair do período "pré-T" (antes do uso da testosterona) para a transição de gênero corporal.

Com isso, não se quer inferir que homens trans "que podem pagar" por uma transição medicamente assistida não enfrentem experiências de sofrimento, dores difíceis de quantificar, expulsões dos espaços ou outras dificuldades para a vivência da transexualidade, seja com ou sem o uso de planos de saúde para o atendimento com profissionais no setor privado, ou até no posto de saúde do bairro (a partir de outra rede de contatos facilitadores). Mas que ao se dispor de diferentes capitais simbólicos e sociais (Bourdieu, 1998), há uma maior ou mais rápida entrada em manejos corporais desejados que diminuem o sofrimento sociologicamente 
produzido, e colocam esses homens em posições de gênero desejadas. Essa condição reflete, imediatamente, nas relações em que estão inseridos ao serem confrontados com as normas de gênero a partir da legitimidade que reivindicam.

Henrique (18 anos) é um caso emblemático a respeito dos capitais necessários para dar progresso à transição, bem como a das violências e dificuldades que surgem ao acioná-la no seio familiar e publicamente em meio às instituições e à rua. Em nossa primeira entrevista, contou que fora expulso de casa ainda menor de idade. Seus pais o rejeitaram por se reconhecer como homem trans, embora não aceitem essa identidade como válida, considerando-o apenas "sapatão". ${ }^{23}$ Ele diz de maneira curta, mas eloquente:

eles falaram que eu não tinha mais família, que eu não tinha mais mãe, eu não tinha mais irmãos, eu não tinha mais nada, que não queria saber, que eu deveria procurar outra pessoa pra viver, isso com 14 anos (Henrique, em entrevista, set. 2015).

Fora desse círculo de suporte, ele encontrou apoio com alguém considerado "da família", embora sem vínculo consanguíneo. Mesmo morando com sua "família adotiva" desde essa idade, sua identidade de homem trans com a assunção de um nome próprio masculino $e$ o início da transição de gênero não se refletiu por um bom tempo, sem o início da hormonização. Enquanto trabalhava em empregos que lhe pagavam menos da metade de um salário mínimo, e ainda sendo identificado como mulher, sem traços masculinos, não tem nenhuma possibilidade de realizar manejos corporais. Apenas com o apoio de amigos gays, lésbicas e transgêneros é que começaria a conhecer uma rede de vendedores de receitas e ampolas. É a partir dessa "ponte" que ele encontra o caminho para ser trilhado em direção aos hormônios.

${ }^{23}$ A noção de "sapatão" tem significado popular ao designar de maneira jocosa $e$ marginal mulheres lésbicas, as ligando à masculinidade. O termo também alcançou entre a população de lésbicas uma ressignificação política reocupada identitariamente no Brasil. 
Quando da nossa terceira entrevista, Henrique conta que havia apenas um mês e quinze dias que estava fazendo uso de Deposteron (Laboratório Ems). As três aplicações que já utilizara continham cada uma $200 \mathrm{mg}$ de solução oleosa injetável de cipionato de testosterona. Essa é uma das marcas mais simples por concentrar apenas um éster. Outras marcas são compostas de até três ésteres, o que possibilita maior duração das substâncias sintéticas no organismo, como os interlocutores bem relataram. Explicando sobre as dificuldades de seu acesso aos hormônios, Henrique detalha uma trajetória exaustiva.

Eu tenho um colega que usava essa Deposteron e ele não estava gostando porque estava ficando muito gordinho $e$ parou de tomar Depo e começou a tomar a Durateston. E eu comprei a ele as primeiras, as primeiras duas ampolas e, aí, eu ganhei mais uma caixa de uma colega minha e agora eu comprei. Eu sei nem se pode falar esse tipo de coisa, mas como a gente não tem acesso e como aqui no estado não tem ambulatório, não tem centro de referência, os médicos se rejeitam a atender porque não sabem o que está acontecendo... Fui numa médica, olhei pra ela e disse que ia denunciar ela ao Conselho por ela estar me negando atendimento, né?! E ela disse que ia atender, aí passou um monte de exames lá, mas eu não tive paciência para esperar a receita e comecei a tomar antes de ela receitar. E, antes dela, comprei uma receita a uma colega minha [...], e vou comprar a caixa de Deposteron com a receita (Henrique, em entrevista, set. 2015).

Durante essa entrevista, Henrique já havia começado a trabalhar numa empresa com carteira de trabalho assinada, cumprindo horários e satisfeito com o ambiente de emprego, que, segundo detalha, não tem problemas com sua transexualidade. Relatou que, antes dessa atividade, esteve em outras nas quais fora chamado pelo nome feminino, além de ter sofrido violências diversas, incluindo uma na qual fora humilhado continuadamente por colegas de trabalho e chefe. Isso o levou a não reclamar nenhuma remuneração após um mês de trabalho, diz que havia 
"deixado pra lá". Retornar para cobrar seu salário não valeria a pena diante das violências que sofrera e que informam quais são os "homens de verdade".

Como se pôde perceber, seja comprando ampolas diretas, receitas para compras em farmácias, idas a médicos no setor privado, o acesso à hormonização envolve capital financeiro $e$ social, no tocante às redes de contatos. Os amigos de Henrique foram aliados importantíssimos. É possível perceber ainda que, embora a presença de dinheiro tecnicamente propiciasse a compra/venda desse material, apenas com uma rede de confiança pôde-se acessar o vendedor. Não foi possível acompanhar nenhuma negociação dessa natureza, mas os relatos são ricos nessa disposição e demonstram agências possíveis para a construção de corpos e de identidades, mas também um cenário que não assiste àqueles que não podem pagar pelo acompanhamento médico. Além disso, aparece como um indicativo da ineficiência da abrangência pelo setor público das políticas de saúde e de trabalho voltadas para a população trans.

\section{Nota final: atenção à saúde e despatologização da transexualidade}

As compras de ampolas de testosterona, possivelmente adulteradas, no mercado extraoficial podem ser riscos tomados como medida urgente de "fazer emergir o masculino" corporalmente, de ativar os mensageiros do masculino, os hormônios. Com isso, essa emersão narrada é condizente com a transição de gênero sendo entendida pelos homens trans como um processo identitário e corporal de ascensão de si mesmo, e não como um itinerário de cura que é aplicado a doentes mentais. Entretanto, políticas de saúde voltadas para a população transexual e transgênera constituem caminhos, técnicas e burocracias a serem seguidas, seja dentro da oficialidade dos protocolos ou fora de seu alcance para alcançar a assistência à saúde. Tais protocolos acabam atuando capilarmente quando homens trans se veem necessitando iniciar sem acompanhamento médico (mas com ajuda de amigos) um manejo corporal que não prescinde de um acúmulo e de uma 
construção de um conhecimento sobre o corpo. Ao contrário de "transformar", o hormônio é visto "adequando" ao externo algo que existe "internamente", como objetivam os interlocutores. Uma experiência que mesmo assistida por redes de suporte $e$ acompanhamento médico pode ser composta por práticas exaustivas, emoções e violências difíceis de vivenciar.

Assim, os movimentos em torno da reflexão e da proposição pela despatologização da transexualidade enquanto "disforia de gênero" ou "transexualismo" não podem ser entendidos de maneira simplista. André Oliveira (2015) mostrou que homens trans encontram-se numa situação controversa nesse sentido: enquanto esses sujeitos não reclamam estar doentes, admitem não abrir mão da patologização para não perder o acesso à saúde que dispõem. Assim, tem-se produzido o discurso da "despatologização estratégica e responsável", principalmente porque se teme o total abandono médico pelo Estado brasileiro (Oliveira, 2015:126). Quando Guilherme Almeida e Daniela Murta (2013) se perguntam como garantir e ampliar o acesso à saúde de pessoas trans quando da possível despatologização aqui referida, nos insta, pesquisadores, ativistas e profissionais de saúde, a pensar uma assistência dentro do escopo que o SUS já oferece para o cuidado em geral. Além disso, desafia os conhecimentos de cunho socioantropológico e em saúde a se unirem para refletir e realizar pesquisas que auxiliem essas pessoas a superarem quadros de sofrimento e desorganização social.

Cabe não rejeitar a assistência médica, mas trazer em seu processo a autonomia do sujeito que vivencia as transições de gênero ao constituir uma atenção à saúde que possibilite que sejam aplicados os parâmetros presentes desde a formação democrática histórica da saúde pública brasileira com a Constituição de 1988. E, com isso, articular um cuidado em saúde que esteja atento à medicalização que patologiza sem retirar o direito à saúde das pessoas trans. As noções de equidade, universalidade, integralidade $e$ gratuidade incrustadas no SUS, e nítidas bases para o desenvolvimento de um serviço de qualidade e igualitário, não 
podem se concretizar com maiores investimentos financeiros $e$ formação continuada para os profissionais.

Uma política integral de saúde que não observe a dificuldade de inserção no mercado de trabalho durante e depois do acesso médico que, por consequência, pode desembocar em problemas de saúde relacionados à fome e às violências física e simbólica, não supre uma preocupação completa com a falta de dignidade humana para viver a vida acarretada por esse cenário vilipendioso de desumanização. Com isso, estamos ainda mais próximos da ampliação do conceito de saúde presente na $8^{\mathrm{a}}$ Conferência Nacional de Saúde (Brasil, 1986) que embasou a criação do Sistema Único de Saúde brasileiro. Isto é, a necessidade premente de ver a saúde como o resultado de condições de alimentação, habitação, educação, renda, trabalho, lazer e liberdade além do acesso aos serviços de atenção.

Não pretendemos dar respostas nem dizer quais caminhos devem ou não ser seguidos para que a população trans alcance cidadania plena no que compete a seu cuidado em saúde. Este trabalho deve ser realizado pelo conjunto organizado da sociedade e dos movimentos sociais que seja composto pelas próprias pessoas trans, ativistas ou não, por médicos e outros profissionais de saúde e do direito, por gestores, e pela contínua ação do controle social sob os serviços de saúde, sua organização, financiamento e oferta. Esta pesquisa buscou descrever e analisar a relação que homens trans constroem com noções de terapia quando de seus processos de hormonização, e, com isso, como engajam-se no cenário da medicalização da transexualidade. Mostramos homens trans de diferentes origens não se vendo como doentes, em relações estreitas com o conhecimento científico médico, vivendo suas vidas apesar das dificuldades acarretadas por estruturas de poder que lhes informam que eles não são humanos o suficiente em razão do gênero. 


\section{Referências bibliográficas}

ABEM. Associação Brasileira de Endocrinologia e Metabologia. Hipogonadismo Masculino Tardio (Andropausa): Tratamento. 2004, (Projeto Diretrizes).

ALEXANDRE, Juliana. Emoções, documentos e subjetivação na construção de transexualidades em João Pessoa/PB. Dissertação de mestrado, Antropologia Social, UFRN, 2015.

ALMEIDA, Guilherme. "Homens trans": novos matizes na aquarela das masculinidades? Revista Estudos Feministas (20)2, FlorianópolisSC, UFSC, 2012, pp.513-523.

; MuRTA, Daniela. Reflexões sobre a possibilidade da despatologização da transexualidade e a necessidade da assistência integral à saúde de transexuais no Brasil. Sexualidad, Salud y Sociedad, n¹4, , Rio de Janeiro, 2013, pp.380-407.

AssociaÇão de Psiquiatria Americana (APA). Manual Diagnóstico e Estatístico de Transtornos Mentais, edição 5 [http://goo.gl/oQorTq acesso em 19 de maio 2015].

ÁvILA, Simone. FTM, transhomem, homem trans, trans, homem: A emergência de transmasculinidades no Brasil contemporâneo. Tese de doutorado, Ciências Humanas, UFSC, 2014.

BARBOSA, Bruno. Imaginando trans: saberes e ativismos em torno das regulações das transformações corporais do sexo. Tese de doutorado, Antropologia Social, USP, 2015.

BARNHART, Robert. The Barnhart Dictionary of Etymology. Hackensack, Grey House Publishing, 1988.

BENTO, Berenice. A (re)invenção do corpo: gênero e sexualidades na experiência transexual. Rio de Janeiro, Garamond, 2006.

. Gênero: uma categoria cultural ou diagnóstica? In: ARILHA, M.; LAPA, T. de S.; PISANESCHI, T. C. (org.). Transexualidade, travestilidade e direito à saúde. São Paulo, Oficina Editorial, 2010, pp.167-198.

Brasil: país do transfeminicídio. CLAM, 2014 [http://www.clam.org.br/uploads/arquivo/Transfeminicidio_Berenice _Bento.pdf - acesso em 10 mar 2016].

BouRdieu, Pierre. O poder simbólico. 2. ed. Rio de Janeiro, Bertrand Brasil, 1998. 
BRASIL. Ministério da Saúde e Ministério da Previdência e Assistência Social. Relatório Final da 8ª . Conferência Nacional de Saúde, 1986.

BRASIL. Secretaria de Vigilância Sanitária. Portaria n. 344. Aprova o Regulamento Técnico sobre substâncias e medicamentos sujeitos a controle especial, 1998.

Butler, Judith. Problemas de gênero. Feminismo e subversão da identidade. Rio de Janeiro, Civilização Brasileira, 2008.

CONNELL, Raewyn. Rethinking gender from the South. Feminist Studies, vol. 40, n⿳3, College Park, MD, University of Maryland, 2014, pp.518-539.

CONNELL, Raewyn. Transexual Women and Feminist Thought: Toward New Understanding and New Politics. Signs: Journal of Women in Culture and Society (37)4, Boston, MA, Northeastern University, 2012, pp.857-881.

CONITEC. Comissão Nacional de Incorporação de Tecnologias no SUS. Ministério da Saúde. Relatório n. 69. Trata da incorporação de novos procedimentos relativos ao Processo Transexualizador no âmbito do SUS, 2012.

CONRAD, Peter. The Medicalization of Society: On the Transformation of Human Conditions into Treatable Disorders. Baltimore, The Johns Hopkins University Press, 2007.

DINIZ, Debora; CASTRO, Rosana. O comércio de medicamentos de gênero na mídia impressa brasileira: misoprostol e mulheres. Cad. Saúde Pública (27)1, Rio de Janeiro, Escola Nacional de Saúde Pública, 2011, pp.94-102.

FONSECA, Claudia. O anonimato e o texto antropológico: dilemas éticos e políticos da etnografia "em casa". In: SCHUCH, P.; VIEIRA, M. S.; PETERS, R. (org.). Experiencias, dilemas e desafios do fazer etnográfico contemporâneo. Porto Alegre, Editora da UFRGS, 2010, pp.205-227.

Foucault, Michel. História da Sexualidade: a vontade de saber, vol. 1. Rio de Janeiro, Grall, 1988 [1976].

. A governamentalidade. In: . Microfísica do poder. 25. ed. São Paulo, Graal, 2012, pp.407-431.

HALl, Stuart. Sin garantías trayectorias y problemáticas em estudios culturales. Popayán-Colombia, Envión Editores, 2010. 
HARAWAY, Donna. "Gênero" para um dicionário marxista: a política sexual de uma palavra. cadernos pagu (22), Campinas-SP, Núcleo de Estudos de Gênero-Pagu/Unicamp, 2004, pp.201-246.

LANGDON, Esther Jean. Representações de doenças e itinerário terapêutico dos Siona da Amazônia colombiana. In: SANTOS, R. V.; COIMBRA Jr., C. E. A. (org.). Saúde e Povos indígenas, Rio de Janeiro, Fiocruz, 1994, pp.115-142.

MARIANI NetO, C. et al. Use of misoprostol for labor induction in stillbirth. Rev. Paul. Med., 105(6), São Paulo, 1987, pp.325-8.

MAUSS, Marcel; HUBERT, Henri. Esboço de uma teoria geral da magia. In: Sociologia e Antropologia, São Paulo, Cosac \& Naify, 2003 (1904), pp.47-181.

Mello, Luiz et alii. Políticas de saúde para lésbicas, gays, bissexuais, travestis e transexuais no Brasil: em busca de universalidade, integralidade e equidade. Sexualidad, Salud y Sociedad, $\mathrm{n}^{\circ}$ 9, Rio de Janeiro, 2011, pp.7-28.

MEYEROWITZ, Joanne Jay. How sex changed: a history of transsexuality in the United States. Cambridge, Harvard University Press, 2002.

MURTA, Daniela A. Os desafios da despatologização da transexualidade: reflexões sobre a assistência a transexuais no Brasil. Tese (Doutorado em Saúde Coletiva), UERJ, Rio de Janeiro, 2011.

OliveirA, André L. G. Somos quem podemos ser: os homens (trans) brasileiros e o discurso pela (des)patologização da transexualidade. Dissertação (Mestrado em Ciências Sociais), UFRN, Natal, 2015.

ORGANIZAÇÃo Mundial de Saúde (OMS). Classificação Estatística Internacional de Doenças e Problemas Relacionados com a Saúde, edição 10. CID-10. [https://www.cid10.com.br/ - acesso em março de 2015].

ORGANIZAÇÃO Mundial de Saúde (OMS). International Classification of Diseases and Related Health Problems, 10th Edition. ICD-10. [https://icd.who.int/browse10/2010/em - acesso em março de 2015].

ORGANIZAÇÃO Mundial de Saúde (OMS). International Classification of Diseases for Mortality and Morbidity Statistics, 11th Edition. ICD-11. [https://icd.who.int/icd11refguide/en/index.html - acesso em janeiro de 2019].

OudSHOORN, Nelly. Beyond the Natural Body. London and New York, Routledge, 1994. 
PorTo, Rozeli M.; SouZA, Cassia H. D. Percorrendo caminhos da angústia: itinerários abortivos em uma capital nordestina. Revista Estudos Feministas, vol. 25, n², Florianópolis/SC, 2017, pp.593-616.

REZENDE, Joffre Marcondes de. Terapia, terapêutica, tratamento. Revista de Patologia Tropical, [S.1.], vol. 39, n², 2010, pp.149-150 [https://goo.gl/d9UajJ - acesso em 15 mai 2016].

ROHDEN, Fabíola. O império dos hormônios e a construção da diferença entre os sexos. História, Ciências, Saúde - Manguinhos, vol. 15, supl., Rio de Janeiro, 2008, pp.133-152.

ROSENBERG, Charles. The tiranny of diagnoses: especific entities and individual experience. In: . Our present complaint: American medicine, then and now. Baltimore, John Hopkins University Press, 2007, pp.13-37.

RuBIN, Henry. Self-Made Men: Identity Men and Embodiment among transmen. Nashville, Vanderbilt University Press, 2003.

SARTI, Cynthia A. Saúde e Sofrimento. In: Martins, C. B.; DuARTE, L. F. D. (org.). Horizontes das ciências sociais no Brasil: Antropologia. São Paulo, ANPOCS, 2010, pp.197-224.

SIMÕES, Júlio A.; CARRARA, Sérgio. O campo de estudos socioantropológicos sobre diversidade sexual e de gênero no Brasil: ensaio sobre sujeitos, temas e abordagens. cadernos pagu (42), Campinas-SP, Núcelo de Estudos de Gênero-Pagu/Unicamp, 2014, pp.75-98.

TRAMONTANO, Lucas. A fixação e a transitoriedade do gênero molecular. Horizontes Antropológicos, ano 23, $\mathrm{n}^{\circ}$ 47, Porto Alegre, 2017, pp.163-189.

VIEIRA, Cleiton. Entre viver e esperar viver: corpo e identidade na transição de gênero de homens trans. Dissertação (Mestrado em Antropologia Social), UFRN, Natal, 2015.

; BARROS, Tatiane Vieira. Antropólogos/as e etnografias diante de processos de adoecimento e medicalização no Brasil - por uma reflexão prática em defesa do SUS. Equatorial - Revista do Programa de Pós-Graduação em Antropologia Social da UFRN, vol. 4, n 7, Natal, 2017, pp.8-23.

WPAHT. Associação Mundial Profissional para a Saúde Transgênero. Normas de atenção à saúde das pessoas trans e com variabilidade de gênero [https://goo.gl/ozfOpv - acesso em 4 de set. 2015]. 